\title{
Secondary conditions following spinal cord injury in a population-based sample
}

\author{
Renee L Johnson, Kenneth A Gerhart, Jeannie McCray, Jean C Menconi and Gale G Whiteneck
}

Craig Hospital, 3425 South Clarkson Street, Englewood, CO. 80110, USA.

\begin{abstract}
This prospective study investigates the frequency of both medical and non-medical complications reported by the population based cohort of SCI survivors reported to the Colorado Spinal Cord Injury Early Notification System (ENS). Persons reported to the ENS between January 11986 and December 31 1993, representing the broad spectrum of all severities of spinal cord injury and potential complications, were solicited to participate in comprehensive follow-up interviews at their first, third and fifth year post injury. Hospitalizations of a week or longer were experienced by more than $10 \%$ of the participants at each of the three interview years. Similarly, the medical complications of spasticity or pain were reported by more than $25 \%$ of the participants, and pressure sores were reported by more than $10 \%$ at all three time periods. The chief non-medical complications (conditions) were financial concerns and transportation problems. Although these reported medical and non-medical complications present significant obstacles to be overcome, less than three percent of those surveyed at any of the time periods reported experiencing depression; and only $14 \%$ rated their quality of life as being poor.
\end{abstract}

Keywords: spinal cord injury; follow-up studies; outcomes; spinal cord injury complications; secondary conditions

\section{Introduction}

Improvements in early post-injury care and rehabilitation have eliminated or minimized many of the early complications that typically accompany those who have a new spinal cord injury. Indeed, advances in such wide ranging areas as cardiopulmonary resuscitation, antibiotic therapies, spinal fracture immobilization, neurodiagnosis, and the evaluation and management of the neuropathic bladder have greatly decreased such injury-related complictions as early death from respiratory insufficiency, acute skin breakdown, urinary tract infections, renal failure and septicemia, and fracture instability or bony deformity.

However, despite these advances in early care, much is still to be learned about the longer-term complications which persons surviving with spinal cord injuries face. One recent study which examined the costs incurred by a group of 115 survivors during the first 2 years following their injuries catalogued $\$ 2$ million in expenses which were directly attributable to secondary medical complications. ${ }^{1}$ Another study reported that charges for rehospitalization alone averaged $\$ 5255$ annually, ${ }^{2}$ while a third found overall annual followup costs to range from over $\$ 9000$ to more than $\$ 95,000$ per individual per year, based on the SCI survivor's age and level of injury. ${ }^{3}$ Indeed, reports like these suggest that long-term spinal cord injury survivor's complications and the prevention and

Correspondence: RL Johnson treatment of those complications is an important, costly, and seemingly under-addressed problem.

A broad range of secondary complications have been reported. Fuhrer examined a sample of SCI survivors injured for an average of 10 years. ${ }^{4}$ Pressure sores were identified in $32 \%$ of those surveyed, urinary tract infections (UTI's) in 37\%, and joint degeneration in more than $50 \%$. In another study, examining survivors injured even longer, between 20 and 45 years, revealed many of these same problems were still present. Pressure sores were present in $23 \%$ of those examined, and urinary tract infections in $20 \%$. Respiratory and cardiovascular complications were also prevalent, as were a host of psycho-social issues. ${ }^{5}$ From the Model SCI Systems' follow-up database, UTIs, renal calculi, scoliosis, pressure sores and surgical repair of pressure sores were a few of the complications that increased among all SCI survivors over time. ${ }^{6}$

Clearly, in the months and years following the acute trauma, ongoing complications create huge additional expenses, and present new problems and challenges to spinal cord injury survivors and their health care providers. Because these complications greatly increase the costs of long-term care, drain limited health care resources, limit survivor's productivity, and decrease their quality of life, the importance of minimizing them is obvious. The study presented here, therefore, examines both the medical and non-medical complica- 
tions experienced by a population-based cohort of persons at their first, third and fifth years following injury.

\section{Methods}

This study investigates the frequency of both medical and non-medical complications reported by the population-based cohort of SCI survivors reported to the Colorado Spinal Cord Injury Early Notification System (ENS). In Colorado, the ENS, conducts population-based spinal cord injury surveillance. ${ }^{7}$ Incident cases of SCI are included in the surveillance data set if they meet all of the criteria in the following case definition: (1) The injury is caused by trauma, which can range from the classic motor vehicle crash to surgically induced injury; (2) The injury is sustained by a Colorado resident, whether the injury event occurred within the state or not; (3) The injury results in some degree of spinal cord related motor, sensory, bowel and/or bladder impairment; this impairment can be either temporary or permanent. All persons meeting these criteria whose injuries occurred between January 1, 1986 and December 31, 1993 were solicited to participate in comprehensive follow-up interviews at their first, third and fifth year post injury.

The follow-up questionnaire used to elicit information about both medical and non-medical complications consisted of three parts. Medical complications were collected using the National Spinal Cord Injury Model Systems Follow-up Questionnaire. ${ }^{8}$ The Craig Handicap Assessment and Reporting Technique $(\text { CHART })^{9}$ was used to measure how a person spends his or her time and the amount of attendant services utilized. ${ }^{10}$ Finally, the ENS follow-up data collection tool was used to obtain information concerning a variety of additional complications, including perceived health problems, such as pain, increased spasticity, neurological deterioration, and psychosocial problems. Barriers to successful functioning such as equipment, transportation, and financial problems were also assessed. The ENS data collection tool incorporates both closed and open ended questions. Data were combined across these three sources. Data must have been collected using all three instruments for the individual to be included in this study.

Follow up data were collected via telephone interviews. The SCI survivor was interviewed directly whenever possible; in rare instances, where the survivor could not effectively use the telephone, a spouse or family member provided the information.

During the 8 year study period, each of the three survey instruments was administered individually. Some individuals declined to complete the full survey, and not all three data collection instruments were used during the early years of the study. As a result, at each follow-up period, some individuals had only partial data collection. Cases for which only part of the data were available were retained and used to validate the frequencies of reported complications for the set of cases that did have complete data collection. To determine the representativeness of the cohort that completed all three surveys, comparison to the combination of the non-interviewed (those who had been lost-to-follow-up or declined to participate) and partially-interviewed cases was conducted with respect to the age at injury, gender, and to a variable that was chosen to serve as a proxy for injury severity; the utilization of rehabilitation services.

Table 1 displays the percentages of persons from each year who completed follow-up questionnaires. Among the 917 patients identified during the study period, 64 had died prior to their first anniversary year, leaving 853 persons available for the collection of follow-up data. Seven hundred and twenty seven $(85 \%)$ of these were successfully contacted and had at least a portion of their data collection completed. For 357 individuals $(41.85 \%)$ a complete complement of the data; all three of the survey forms described above had been collected at the first follow-up year. Similarly, 572 survivors had crossed their third year anniversary by December 31 1994. Four hundred and seventy-two $(83 \%)$ of the survivors were successfully contacted and had at least a portion of their data collection completed, while $269(47 \%)$ completed all three survey instruments at the third follow-up year. Finally, 335 persons had crossed their fifth year anniversary by December 31 1994. Of these 287 $(86 \%)$ were successfully contacted and had at least a portion of their data collection completed. One hundred and seventy (51\%) had a complete complement of the data collected at their fifth follow-up year. Table 2 describes these individuals demographically, at each of the follow-up intervals.

The patients in Table 1 with complete data collection were compared to those with partial and/ or no data collection. Differences in characteristics among those persons who had complete interviews and those who had either a partial or no interview during

Table 1 Numbers and percentages of cases participating in follow-up at each time interval

\begin{tabular}{lcccccr}
\hline $\begin{array}{l}\text { Follow-up } \\
\text { year }\end{array}$ & $\begin{array}{c}\text { Number of } \\
\text { indentified } \\
\text { cases }\end{array}$ & $\begin{array}{c}\text { Number of } \\
\text { deaths prior to } \\
\text { follow-up year }\end{array}$ & $\begin{array}{c}\text { Number of } \\
\text { expected } \\
\text { follow-up cases }\end{array}$ & $\begin{array}{c}\text { Number of cases } \\
\text { with complete } \\
\text { data collection }\end{array}$ & $\begin{array}{c}\text { Number of cases } \\
\text { with partial } \\
\text { data collection }\end{array}$ & $\begin{array}{c}\text { Number of } \\
\text { cases lost to } \\
\text { follow-up }\end{array}$ \\
\hline 1 & 917 & $64(6.9 \%)$ & 853 & $357(41.9 \%)$ & $370(43.4 \%)$ & $126(14.8 \%)$ \\
3 & 625 & $53(8.5 \%)$ & 572 & $269(47.0 \%)$ & $203(35.5 \%)$ & $100(17.5 \%)$ \\
5 & 368 & $33(9.0 \%)$ & 335 & $170(50.7 \%)$ & $117(34.9 \%)$ & $48(14.3 \%)$ \\
\hline
\end{tabular}


each follow-up period were identified. There was a significant difference $(P<0.01)$ in the mean age at injury, with those who had completed all data collection having a mean age of 33 , while those with incomplete or no data collection had a mean age of 37 years. Additionally, persons who were injured severely enough to have required inpatient rehabilitation at the time of their original injuries were over-represented in the complete data collection sample $(P<0.001)$. Eighty-six percent of that group had inpatient rehabilitation, while only $65 \%$ of the incomplete or no data collection group had undergone inpatient rehabilitation. Differences in gender, however, were not significant. Males comprised of $76 \%$ of the complete data collection group and of $79 \%$ of the partial or no data collection group averaged across all three intervals.

Despite these differences in the demographics

Table 2 Demographic characteristics of Individuals Interviewed

\begin{tabular}{|c|c|c|c|}
\hline & Year 1 & Year 3 & Year 5 \\
\hline Mean Age. & 33.2 & 32.9 & 31.7 \\
\hline \multicolumn{4}{|l|}{ Age groupings } \\
\hline$<15$ years & $3.6 \%$ & $2.2 \%$ & $1.8 \%$ \\
\hline $15-44$ years & $76.5 \%$ & $79.9 \%$ & $83.5 \%$ \\
\hline $45-64$ years & $13.2 \%$ & $13.0 \%$ & $10.6 \%$ \\
\hline$>64$ years & $6.7 \%$ & $4.8 \%$ & $4.1 \%$ \\
\hline Gender: \% Male & $75.6 \%$ & $76.2 \%$ & $74.7 \%$ \\
\hline \multicolumn{4}{|l|}{ Injury levels: } \\
\hline Cervical & $52.7 \%$ & $49.4 \%$ & $48.2 \%$ \\
\hline Thoracic 1 -Thoracic 6 & $11.2 \%$ & $12.3 \%$ & $11.2 \%$ \\
\hline Thoracic 7 -Thoracic 12 & $18.8 \%$ & $22.3 \%$ & $24.1 \%$ \\
\hline Thoracic-specific level unknown & $1.4 \%$ & $1.1 \%$ & $1.2 \%$ \\
\hline $\begin{array}{l}\text { Lumbar-sacral } \\
\text { Injury severity groupings: }\end{array}$ & $16.0 \%$ & $14.9 \%$ & $15.3 \%$ \\
\hline Cervical, functionally complete* & $32.0 \%$ & $30.0 \%$ & $31.1 \%$ \\
\hline $\begin{array}{l}\text { Non-cervical, functionally } \\
\text { complete* }\end{array}$ & $31.7 \%$ & $35.7 \%$ & $37.6 \%$ \\
\hline $\begin{array}{l}\text { All levels, functionally } \\
\text { incomplete** }\end{array}$ & $34.7 \%$ & $33.8 \%$ & $30.6 \%$ \\
\hline Severity unknown & $1.7 \%$ & $0.7 \%$ & $0.6 \%$ \\
\hline $\begin{array}{l}\text { Participated in in-patient } \\
\text { rehabilitation following initial injl }\end{array}$ & $82.9 \%$ & $85.1 \%$ & $85.9 \%$ \\
\hline
\end{tabular}

*ASIA Impairment Scales A,B and C.

**ASIA Impairment Scales A,B and $\mathrm{C}^{13}$ between the complete data collection and the partial or no data collection group, there was no difference found in the rates of complications reported between the complete and partial data collection groups. Comparisons of complications reported between the two groups were made separately for each year of analysis and each method of data collection. In comparing the rates of 19 different medical complications reported on the ENS data collection tool across the three year of analysis, only one complication showed significant differences between the two groups: self-reported neurological change at year three $(22.4 \%$ among incompletely interviewed persons; $9.3 \%$ among those completed all three interview forms; $P<0.05)$. For the same 19 medical complications reported on the National Spinal Cord Injury Model Systems Follow-up Questionnaire across the three years of analysis, no complications showed a significant difference $(P<0.05)$ between the two groups. Since the one significant difference that was found could easily have occurred due to chance among the 114 comparisons that were made, it was concluded that the group of participants with complete data collection was not biased from the group of participants with partial data collection with respect to the types and frequency of complications reported. Consequently, because further analyses required complete data collection across the three survey instruments, the cases with partial data collection were then excluded. Differences in complication frequencies between the three time periods were tested using a Chi-square test.

\section{Results}

\section{General medical complications information}

The percentage of persons hospitalized for any length of time drops consistently and significantly over the time periods (year 1: $27.2 \%$, year 3: $20.1 \%$, year 5: $18.8 \% ; P<0.05)$. Table 3 displays this rehospitalization data for the three groups in a rate format and compares it to the general United States (US) population in 1990. Additionally, over $10 \%$ of the survivors were hospitalized for more than a week at each of the time intervals (year 1: $15.7 \%$, year 3: $11.9 \%$, year 5: $12.4 \%$ ). There were no significant differences between the percentages of persons experi-

Table 3 Number of hospitalization rates per 1000 population

\begin{tabular}{|c|c|c|c|c|c|c|c|c|c|c|c|}
\hline \multirow[b]{2}{*}{$\begin{array}{c}\text { Age } \\
\text { group }\end{array}$} & \multirow[b]{2}{*}{$\begin{array}{c}\text { General } \\
\text { US } \\
(1990)^{11} \\
\text { Rate }\end{array}$} & \multicolumn{3}{|c|}{ Year 1} & \multicolumn{3}{|c|}{ Year 3} & \multicolumn{3}{|c|}{ Year 5} & \multirow{2}{*}{$\begin{array}{l}\text { Three Interval } \\
\text { Adjusted } \\
\text { average times } \\
\text { greater than } \\
\text { the US rate }\end{array}$} \\
\hline & & $\begin{array}{l}\text { Number } \\
\text { hospita- } \\
\text { lized }\end{array}$ & Rate & $\begin{array}{c}\text { Times } \\
\text { greater } \\
\text { than the } \\
\text { US rate }\end{array}$ & $\begin{array}{l}\text { Number } \\
\text { hospita- } \\
\text { lized }\end{array}$ & Rate & $\begin{array}{c}\text { Times } \\
\text { greater } \\
\text { than the } \\
\text { US rate }\end{array}$ & $\begin{array}{l}\text { Number } \\
\text { hospita- } \\
\text { lized }\end{array}$ & Rate & $\begin{array}{c}\text { Times } \\
\text { greater } \\
\text { than the } \\
\text { US rate }\end{array}$ & \\
\hline$<15$ & 43.9 & 2 & 153.8 & 3.5 & 1 & 100 & 3.8 & 1 & 53 & 7. & 4. \\
\hline $15-44$ years & 101.7 & 69 & 252.7 & 2.5 & 39 & 181.3 & 1.8 & 26 & 183.0 & 1.8 & 2.1 \\
\hline $45-64$ years & 133.1 & 17 & 361.7 & 2.7 & 11 & 314.2 & 2.4 & 4 & 222.2 & 1.7 & 2.4 \\
\hline$>65$ years & 327.1 & 9 & 375 & 1.1 & 3 & 230.7 & 0.7 & 1 & 142.8 & 0.4 & 0.9 \\
\hline Total & 113.1 & 97 & 271.7 & 2.4 & 54 & 200.7 & 1.8 & 32 & 188.2 & 1.7 & 2.0 \\
\hline
\end{tabular}


encing these longer hospitalizations during each of the time periods. The medical diagnoses most closely associated with rehospitalization of a week's duration or longer were severe pressure sores in the sacral, trochanteric, ischial, or genital regions $(P<0.05)$, respiratory complications $(P<0.05)$, spinal surgery, such as to repair or replace spinal fixation hardware $(P<0.001)$, and surgery to treat a spinal cord cyst $(P<0.05)$.

Figure 1 addresses the medical complications that were reported at the given follow-up years. At each of the three time periods both problematic spasticity and pain were reported by over one-quarter of the participants. While the complaints of spasticity decreased steadily over the time periods, pain increased. The primary locations that participants reported pain were in the arm/shoulder, neck, and back, with complaints of back pain specifically being the greatest and voiced by over $10 \%$ of the sample each year.

Reports of perceived neurologic deterioration were expressed by about $10 \%$ of the participants at each follow-up contact. Included in this category are reports of both motor loss and decreased bladder and bowel function. In addition to the specific reports of neurologic deterioration, many of the participants complained of numbness or tingling. Finally, autonomic dysreflexia also was reported by more than $5 \%$ of all participants at the first and third intervals. If only those SCI survivors truly at risk for this symptom-those whose initial injuries were at or above the sixth thoracic vertebra - are considered, the percentage of those complaining of this

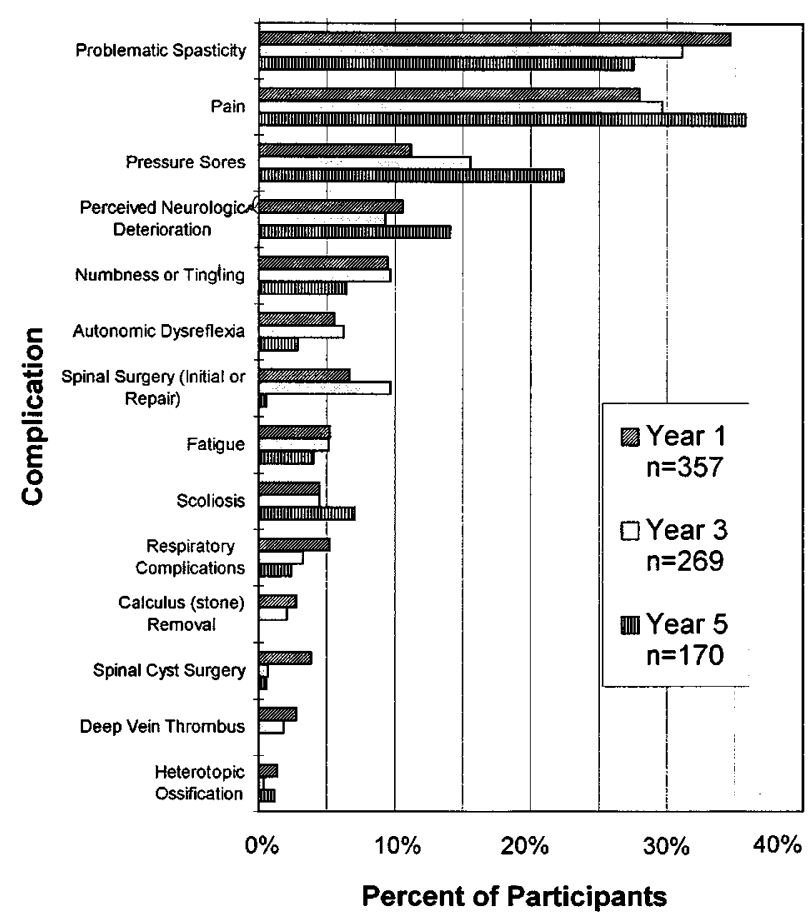

Figure 1 Medical complications by follow-up year symptom increases to $10 \%$ at the first year and $11 \%$ at the third year.

Spinal surgery, both initial and repair, was carried out most often during the first and third year of follow-up and was substantially decreased at the fifth year. Similarly, spinal cyst surgery was most likely to be done early in the follow-up period, with the most reports occurring in the first year following injury. Other complications that decreased in frequency, some significantly so, over the time periods include removal and repair of spinal fixation hardware $(P<0.001)$, rehospitalizations $(P<0.05)$, respiratory complications, and problematic spasticity. A few medical complications that were present but less frequent included fatigue, scoliosis, respiratory complications, kidney and/or bladder calculus removal, deep vein thrombosis, and heterotopic ossification.

Finally, the frequency of reported pressure sores is presented separately in Figure 2. The presence of pressure sores, of any severity at any location, though not statistically significant, increased steadily, over the 5 year period. By year five, sitting sores those located on the sacrum, the ischials, the trochanters or the genitals occurred in over $10 \%$ of the participants. Note that the overall increase in pressure sores located at any place on the body is a reflection of the increasing number of lower extremity sores. These include not only sores related to sitting, but sores at other lower extremity sites as well. In fact, during the entire study period, there was never more than one report of a non-lower extremity sore in any follow-up period. Note also that during the fifth year of follow-

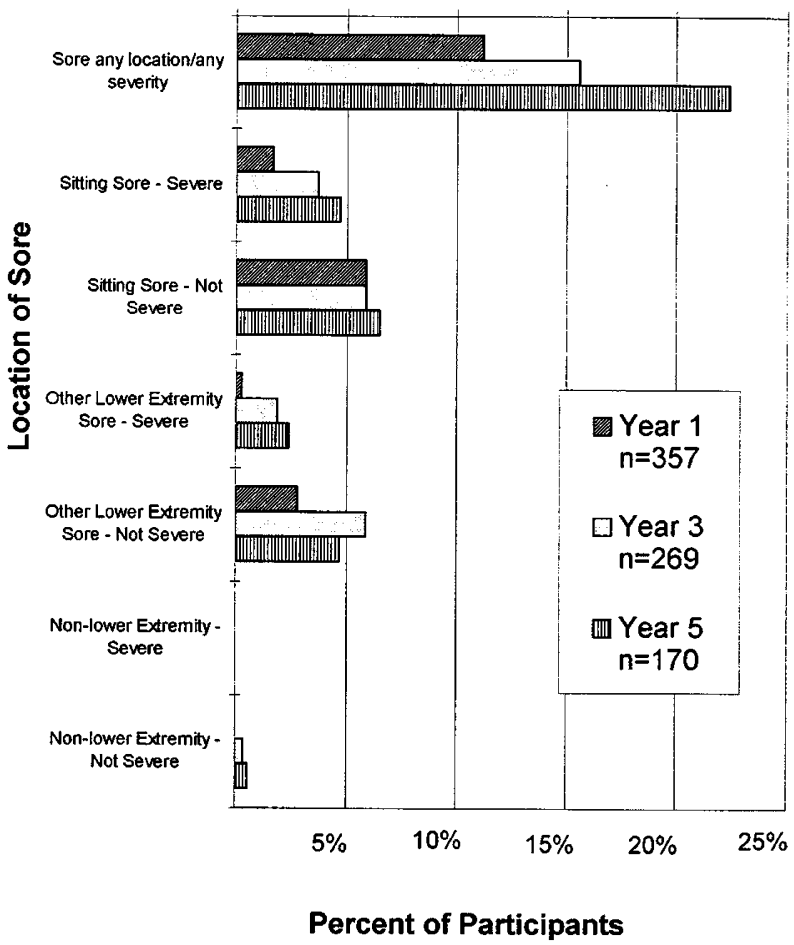

Figure 2 Pressure sores by year of follow-up 
up, 28\% (five out of 18) of those who had a pressure sore in the sitting region also had an additional lower extremity sore. The presence of a concomitant sore was noted during the earlier years as well, but had occurred with lower frequency $(15 \%$ at year one and $16 \%$ at year three).

\section{Non-medical complications}

A substantial percent of the participants expressed non-medical complications as well. As demonstrated in Figure 3, financial concerns topped the list. At all three time periods at least $25 \%$ of the participants reported some type of a financial limitation. These limitations ranged from not being able to secure health insurance, to being unemployed or underemployed, to not being able to purchase the needed equipment. Additionally, durable medical equipment problems posed a substantial concern, increasing significantly between the first and third years postinjury $(P<0.001)$. The unmet need for replacement or repair of a participant's wheelchair topped this category. Similarly, the need for home modifications went unmet even into the fifth year for over $5 \%$ of the study participants.

Reports of financial concerns, the largest category of non-medical issues, were associated with transportation problems at all three intervals $(P<0.01)$, with durable medical equipment problems at the first and third year $(P<0.05)$ and with inability to make necessary home modifications at the first and fifth year $(P<0.05)$. Additionally, by year five the percent of persons reporting increased drug and alcohol use had increased to nearly $10 \%$. Similarly, the percent of persons reporting sexuality concerns had also risen to nearly $10 \%$.

On the other hand, less than three percent of those surveyed at any of the time periods reported that they felt depressed (year 1: $2.2 \%$, year 3: $0.4 \%$, year 5: $1.2 \%$ ), while $15 \%$ or less reported that their quality of life was poor (year 1: $15.1 \%$, year 3: $13.4 \%$, year 5: $13.7 \%$ ) and less than $8 \%$ reported that their adjustment to their spinal cord injury was 'poor' (year 1: $7.2 \%$, year 3: 4.5\%, year 5: 4.7\%). However, reports of pain were associated with reports of poor quality of life at years one and three $(P<0.01)$ and with reports of poor adjustment at all three intervals $(P<0.01)$. Reports of depression on the other hand were associated with the non-medical complications of having transportation problems (year one and three, $P<0.05$ ) and financial problems (year 1, $P<0.05)$.

\section{Discussion}

This study is seemingly the first to address complications of spinal cord injury survivors in a populationbased sample. Good representation was obtained and the use of cases from which partial data was collected substantiates the validity of complication frequencies

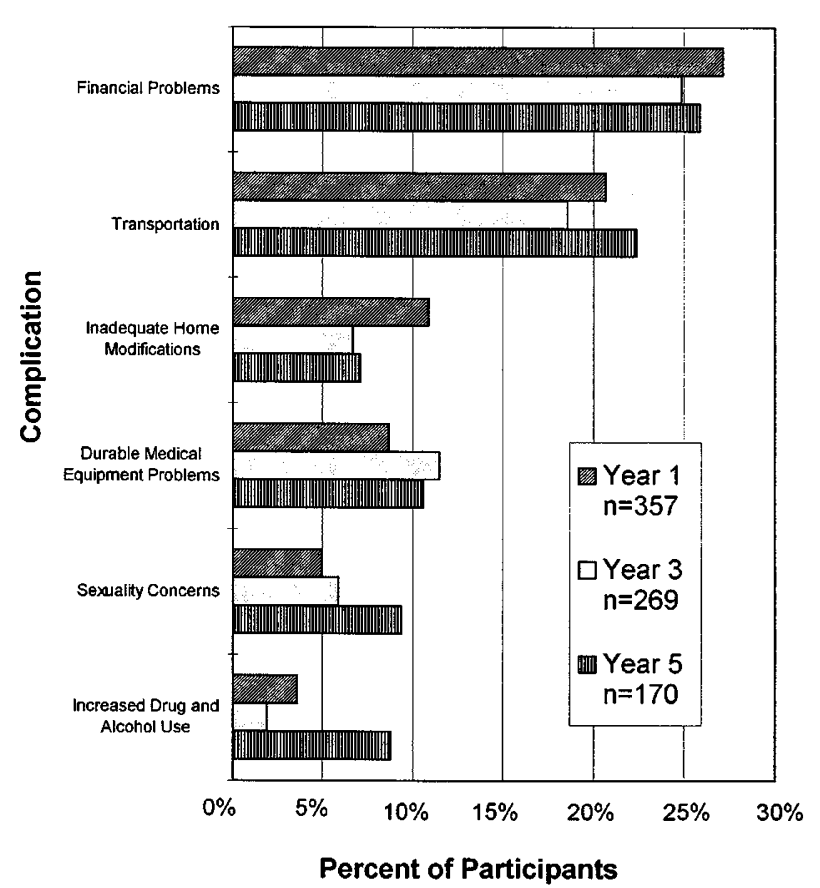

Figure 3 Non-medical complications by year of follow-up

that were reported by those participants who completed all three of the survey instruments.

However, the group of persons who participated in the study was slightly younger and more severely injured than those who did not participate. Both of these differences may well be a function of several phenomena. First, more severely injured persons are more likely to have multiple hospitalizations for both acute and rehabilitation care; thus there are more opportunities to track and locate them. Secondly, these more severely injured people typically have been made aware of the various networks designed to assist them in finding resources and support; they often have a higher perceived need for support. Because the Early Notification System itself has a support component, more severely injured persons tend to be aware of it and thus may be more likely than their seemingly less needy counterparts to actively maintain ongoing follow-up ties. Third, individuals with milder spinal cord injuries are typically more mobile, make fewer contacts with the health care system, and so are much more easily 'lost-to-follow-up'. Finally, it is older persons who are likely to sustain these incomplete injuries. They may be less likely to undergo comprehensive rehabilitation due to the mildness of their injuries, their rehabilitation candidacy, or their funding resources. Older persons also do not provide the typical tracking opportunities that younger persons do: they do not have firmly-rooted parents who know their whereabouts, nor do they have relationships with employers, colleges, or schools which often provide alternative sources for tracking. Clearly, efforts to improve follow-up and increase participation rates in 
further studies will need to minimize these samplingbased limitations.

The overall hospitalization rates for this group of SCI survivors, at years 1, 3, and 5 were 272, 201 and 188 persons per 1000 which ranges from 1.7 to 2.4 times that of the general United States population in $1990 .^{11}$ This increase in hospitalization was disproportionately borne by the younger members of the sample. Much of this greater rate can be attributed to several complications that are closely linked with spinal cord injury: pressure sores, respiratory complications and spinal surgeries.

One medical complication which is of key concern for SCI survivors, but which is conspicuously absent from this study, is urinary tract infection. The presence and high incidence of this particular diagnosis is well documented, ${ }^{5,6,12}$ and its obvious omission here is not because of its insignificance within this population, but rather due to methodological limitations of the study itself. Accurate documentation of UTI's depends upon laboratory testing, and this was not possible in this study which collected all of its data by telephone interview. Consequently, although many study participants (less than $3 \%$ at any follow-up period) did report having what they considered to be bladder infections at the time their interview was conducted, we have made no attempt to scientifically describe UTI's.

In addition to medical diagnoses, a substantial number of non-medical complications were reported. Although this study identifies and tracks these over time, it cannot answer the more important question, 'How are these non-medical complications related to both the incidence and severity of medical complications, rehospitalization's and life satisfaction?' Certainly the availability of funds, transportation and access to appropriate equipment can be expected to impact not only the availability of preventative evaluations and treatment services but also the types of follow-up that individual survivors can participate in. Clearly, further study, focusing on the identification of risk factors and the development of predictive models incorporating both medical and non-medical variables is needed.

When considering how to assist spinal cord injury survivors in decreasing the frequency and impact of complications over the course of their lifetimes, there are three factors to be considered. First, we must understand the prevalence of specific complications. Second, we must understand the significance of individual complications in terms of not only the cost to the survivor and society but also in terms of the impact of the complication on the survivor's quality of life and productivity. Finally, we must learn whether a specific complication is truly preventable. Thus, while spasticity is very prevalent, its impact is quite variable, and its preventability is questionable. Similarly, while financial problems may be both prevalent and significant, it may be difficult to minimize their impact short of broad policy changes at a societal level. The issues of pain and pressure sores, on the other hand, are both of high prevalence and impact, and both may be open to intervention. Clearly further exploration utilizing these three factors is warranted.

Finally, population-based studies such as these need to be conducted for far more than 5 years. Longitudinal research with SCI survivors has only just begun, and is only beginning to hint at some of the long-term issues SCI survivors face. ${ }^{5}$ The true incidence and prevalence of serious complications and conditions can neither be tracked nor understood, nor can their risk factors be identified or their preventions be implemented without a much longer perspective, spanning decades rather than years.

\section{References}

1 Johnson RL, Whiteneck GG, Brooks CA. Cost of traumatic spinal cord injury in a population-based registry. Spinal Cord 1996; 34: 470 - 480.

2 DeVivo MJ, Whiteneck GG, Charles ED. The economic impact of spinal cord injury. In: Stover SL, DeLisa JA, Whiteneck GG (eds). Spinal Cord Injury: Clinical Outcomes from the Model Systems. Aspen Publications: Gaithersburg, MD, 1995, pp $234-$ 267.

3 Menter RR et al. Impairment, disability, handicap and medical expenses of persons aging with spinal cord injury. Paraplegia 1991; 29: 613-619.

4 Fuhrer MJ. Rehabilitation research and training center in community-orientated services for persons with spinal cord injury: a progress report. Houston, TX: the Baylor College of Medicine and the Institute for Rehabilitation Research 1991.

5 Whiteneck GG. et al. Mortality, morbidity, and psychosocial outcomes of persons spinal cord injured more than 20 years. Paraplegia 1992; 30: 617-630.

6 Menter RR, Hudson LM. Effects of age at injury and the aging process. In: Stover SL, DeLisa JA, Whiteneck GG (eds). Spinal Cord Injury: Clinical Outcomes from the Model Systems, Aspen Publications: Gaithersburg, MD, 1995, pp 272-287.

7 Colorado Department of Public Health and Environment. 1994 Annual Report of the Spinal Cord Injury Early Notification System. Colorado Department of Transportation Printing Office: Denver, CO, 1995.

8 National Spinal Cord Injury Statistical Center, The University of Alabama at Birmingham. The Model Spinal Cord Injury Systems' Data Collection Syllabus for the National Spinal Cord Injury Database. Birmingham, AL, 1990.

9 Whiteneck GG et al. Quantifying handicap: a new measure of long-term rehabilitation outcomes. Archives of Physical Medicine and Rehabilitation 1992; 73: 519-526.

10 Whiteneck GG et al. Aging with Spinal Cord Injuiry. Demos Publications: New York, 1993.

11 National Center for Health Statistics. Health, United States, 1995. Public Health Service: Hyattsville, MD 1996, p 199.

12 Cardenas DD, Farrell-Roberts L, Sipski ML, Rubner D. Management of gastrointestinal, genitourinary and sexual function. In: Stover SL, DeLisa JA, Whiteneck GG (eds). Spinal Cord Injury: Clinical Outcomes from the Model Systems, Aspen Publications: Gaithersburg, MD, 1995, pp 120-136.

13 Ditunno JF, Young W, Donovan WH, Creasey G. (1994) The international standards booklet for neurological and functional classification of spinal cord injury. Paraplegia 1994; 32: 70-80. 